\title{
Título do sítio electrónico: Guerra Colonial
}

\section{1-1974}

URL: http://www.guerracolonial.org

\section{Elsa Santos}

\section{OpenEdition}

\section{Journals}

Edição electrónica

URL: http://journals.openedition.org/rccs/596

DOI: $10.4000 /$ rccs.596

ISSN: 2182-7435

\section{Editora}

Centro de Estudos Sociais da Universidade de Coimbra

Edição impressa

Data de publição: 1 dezembro 2008

Paginação: 197

ISSN: 0254-1106

Refêrencia eletrónica

Elsa Santos, «Título do sítio electrónico: Guerra Colonial 1961-1974 », Revista Crítica de Ciências Sociais [Online], 83 | 2008, posto online no dia 01 outubro 2012, consultado o 22 setembro 2020. URL : http://journals.openedition.org/rccs/596 ; DOI : https://doi.org/10.4000/rccs.596 


\section{Espaço Virtual}

\section{Título do sítio electrónico: Guerra Colonial 1961-1974 URL: http://www.guerracolonial.org}

Foi recentemente lançado (a 4 de Fevereiro de 2009) o sítio electrónico "Guerra Colonial 1961-1974”, numa parceria entre a Associação 25 de Abril e a RTP - Rádio Televisão Portuguesa. Baseado na obra "Guerra Colonial" de Aniceto Afonso e Carlos Matos Gomes, o projecto foi co-financiado pelos Ministérios da Ciência, Tecnologia e Ensino Superior, da Educação e da Defesa, pela União Europeia, pela RTP e pela Caixa Geral de Depósitos.

Segundo a mensagem do Presidente da Direcção da Associação 25 de Abril, o Coronel Vasco Lourenço, um dos objectivos deste projecto é "perpetuar a nossa memória colectiva" de um acontecimento determinante da "nossa vivência colectiva”, a guerra em que Portugal se envolveu nas suas colónias de Angola, Guiné e Moçambique.

O sítio põe à disposição dos visitantes um vasto conjunto de textos, dossiers temáticos, galeria de fotografias e vídeos, dados estatísticos, bibliografia e links fundamentais sobre este período marcante da história portuguesa. Dá-nos ainda a conhecer alguns (36) dos "protagonistas" da Guerra Colonial, de ambos os lados dos conflitos, com uma pequena nota biográfica de cada um deles; uma extensa cronologia internacional e nacional, com factos relevantes desde 1943 até 1976; e uma compilação das Resoluções da Assembleia Geral e do Conselho de Segurança da Organização das Nações Unidas, entre 1955 e 1974, sobre os territórios sob administração portuguesa.

De vídeos e documentário, actuais e da época, dos arquivos da RTP, comentados por vários militares, a uma história do 25 de Abril contada pela Associação 25 de Abril, o sítio disponibiliza, de forma simples e bem organizada, e sempre bem documentada com fotografias, informação histórica sobre Portugal, compilada por temas, desde o pós-II Guerra Mundial e o contexto internacional, passando pelas doutrinas, os cenários de guerra, as operações, as armas, as forças portuguesas, as forças dos movimentos de libertação, entre outros temas, terminando com "a guerra nas artes e nas letras" e uma alusão a algumas (muito poucas) obras de cinema e da literatura sobre a Guerra Colonial.

Talvez o sítio aborde mais exaustivamente a dimensão militar em detrimento de outras, talvez pudesse estar mais completo ou ter alguns dos temas mais desenvolvidos e complementados, nomeadamente incorporando mais memórias, testemunhos e arquivos dos países africanos lusófonos envolvidos e uma versão não tão portuguesa da Guerra. Mas, como diz o Coronel Vasco Lourenço "este site não é uma obra acabada" e "nunca o será". Ainda assim, não deixa de ser uma ferramenta importante para preencher as lacunas do ensino da história contemporânea portuguesa aos mais jovens e de se apresentar como uma iniciativa inovadora no sentido de romper com o silêncio que a Guerra Colonial ainda provoca na sociedade portuguesa e de, como referiu o Ministro da Defesa português, Nuno Severiano Teixeira, na sessão de lançamento do sítio electrónico, reconciliar a História com a memória.

Elsa Santos 


\section{Título do sítio electrónico: Worldmapper URL: http://www.worldmapper.org/index.html}

O mundo como nunca foi visto anteriormente: este é o mote e o convite feito pelos mentores do Projecto Worldmapper, sediado na Universidade de Sheffield e Michigan. O seu principal objectivo é produzir mapas ilustrando as diferentes desigualdades inscritas na dimensão espacial. Aqui o espaço não é apenas absoluto e geográfico, mas relativo e relacional.

Tem como ponto de partida o mapa mundi, com base numa distribuição proporcional da área territorial existente. A partir daí, em cada mapa, procede-se à distribuição do peso relativo de cada território com base em cada um dos indicadores estudados. Desta forma a visão do mundo altera-se substancialmente.

A amplitude dos dados disponíveis é assinalável. Cerca de 600 mapas, dos quais $366 \mathrm{em}$ posters em PDF, abarcando uma multiplicidade de temas - transportes, alimentação, produção de bens, trabalho, rendimento, riqueza e pobreza, saúde, entre muitos outros. Assim, é possível encontrar desde a representação mais clássica da população ou da distribuição do rendimento até outros indicadores menos comuns, como a violência (gastos militares, numero de mortes violentas, vitimas de minas pessoais, detidos à espera de julgamento), a polviçãa (emissões de carbono, resíduos nucleares), a aç̧ão (número de sindicalizados, montante de ajuda humanitária, numero de votos de cada país no Fundo Monetário Internacional) ou ainda a destruição (número de espécies extintas ou em risco). Alguns resultados podem surpreender, outros nem por isso. Os próprios dinamizadores do sítio convidam a fazer esse exercício antes de aceder ao mapa do seu interesse. A visualização facilita sobremaneira a compreensão dos diversos fenómenos em presença, o que torna este sítio um instrumento extremamente útil, didáctico e, como tal, de consulta altamente recomendada.

Hugo Dias

\section{Título do sítio electrónico: Seja realista: peça o impossível (Movimento Estudantil Brasileiro) URL: http://sejarealistapecaoimpossivel.blogspot.com}

O slogan do Maio de 1968 francês - e título do blog do historiador e sociólogo da Universidade Federal de Pernambuco, Otávio Luiz Machado - representa o interesse crítico da pesquisa e do debate do movimento estudantil brasileiro, das reformas universitárias e da organização da União Nacional dos Estudantes (UNE) perante os novos desafios e perspectivas para o ensino superior brasileiro. É nesse sentido que a crítica à UNE não passaria em branco, apontando para um caminho que valoriza as expe- riências dos estudantes e militantes no movimento, através das várias pesquisas e recolhas de memórias dos estudantes sessentistas.

O propósito de Machado e de seu grupo de pesquisa é sem dúvida um debate público da memória do movimento estudantil, se diferenciando dos actuais arquivos virtuais da UNE, cuja carga de marketing e alto investimento do governo representam um trabalho menos especializado e em acordo com as posições políticas da organização. 
Os textos do blogue - desde textos do próprio autor, como também diversos textos publicados na comunicação social, apontam para as falhas e mudanças políticas na UNE, evidenciando o processo de crise que paira sobre a organização, principalmente após o início do Governo Lula em 2003, as crescentes manifestações e a consequente criminalização dos movimentos sociais, da qual o movimento estudantil não passou em branco.

O blogue deixa-nos uma questão compartilhada por vários estudantes: se a UNE já não representa os estudantes, quais os caminhos organizativos e associativos a seguir? As novas alternativas de organização estudantil, como a CONLUTE (Coordenação Nacional de Lutas Estudantis). São alternativas ou reproduzem os mesmos problemas da UNE? A resposta não é dada no blogue, mas é inscrita nas práticas e nos novos caminhos alternativos do próprio movimento, impulsionados, certamente, pelas reflexões nos espaços académicos e nos espaços virtuais, como esse blogue.

\section{Pablo Almada}

\section{Título do sítio electrónico: FERVE - Fartos d'Estes Recibos Verdes URL: http://fartosdestesrecibosverdes.blogspot.com/}

Desde o final de 2006 surgiram em Portugal diferentes grupos que pretendem exprimir várias das facetas da precariedade laboral e social. A Plataforma dos Intermitentes do Espectáculo, a Associação dos Bolseiros de Investigação Científica, os Precários Inflexíveis e o FERVE - Fartos destes Recibos Verdes, parecem ser os mais significativos.

O blogue do FERVE é um dos exemplos mais interessantes para pensar o papel que a internet e os espaços de encontro virtual têm tido para estes colectivos. A maior parte dos trabalhadores a recibo verde no nosso país não são verdadeiros trabalhadores autónomos ou independentes. Mas o facto de assim serem considerados (e por vezes auto-representados) afasta-os de uma ligação com sindicatos que estão pensados a partir das formas mais estáveis de vínculo laboral. A realidade dos "recibos verdes", que atinge, calcula-se, cerca de 900 mil pessoas, nunca tinha tido uma expressão organizada. O FERVE, fundado em Março de 2007, ocupou esse espaço e fê-lo através da criação de um blogue. O primeiro passo foi extremamente simples, mas essencial: criar um espaço virtual que contivesse testemunhos de trabalhadores a "falso recibo verde" (esta rubrica, com mais de uma centena de casos, continua sendo a mais concorrida do blogue, que incita os leitores à divulgação das suas "histórias de encantar"). A recolha de histórias, de casos, de narrativas biográficas de precariedade permitiu assim dar visibilidade pública a uma realidade que permanecia escondida, calada, apesar de estar latente.

Como se pode verificar percorrendo os vários posts, este blogue é a âncora do grupo e foi a plataforma a partir da qual se fizeram queixas, petições, protestos por e-mail, cartas e a partir de onde se desenvolveu uma luta no espaço público e mediático que fez, por exemplo, o Governo recuar numa questão relacionada com o IVA. Além dos testemunhos, encontram-se informações práticas sobre os recibos verdes e a legislação associada, informação sobre as iniciativas do grupo, notícias sobre precariedade e ligações com os outros grupos de trabalhadores precários. 
O blogue do FERVE tornou-se um referencial e um lugar de encontro para um segmento importante da força de trabalho em Portugal, tendo cerca de 130 mil visitantes únicos e tendo atin-

gido, no pico da polémica que envolveu JoséSoeiro a alteração das regras do IVA, no mês de Dezembro de 2008, cerca de 3.600 visitas diárias e centenas de comentários. 